\title{
Nutritional status and associated factors among people living with HIV/AIDS in Ghana: cross-sectional study of highly active antiretroviral therapy clients
}

Beauty Mawuenam Nanewortor ${ }^{1}$, Farrukh Ishaque Saah ${ }^{2 *}$, Prince Kubi Appiah ${ }^{1}$, Hubert Amu ${ }^{3}$ and Kwaku Kissah-Korsah ${ }^{4}$

\begin{abstract}
Background: Nutrition among people living with HIV/AIDS (PLWHA) is essential in their care and management as it has implication for their immune function. We examined the nutritional status and associated factors among HIV positive clients accessing Highly Active Anti-Retroviral Therapy (HAART) at a public hospital in Ghana.

Methods: This was a descriptive cross-sectional study of 152 clients. Anthropometric measurements for weight and height were carried out in 2019. Data were analysed using SPSS 22.0. Descriptive and analytical statistics comprising frequency, percentage, and binary logistic regression were adopted in presenting the results.

Results: Seventy-nine percent and $74 \%$ of the clients had good nutrition knowledge and attitude, respectively. Also, $42 \%$ were malnourished (underweight $=13.8 \%$, and overweight $=28.3 \%)$. Clients with primary $(A O R=0.36$, $95 \% \mathrm{Cl}=0.07-1.84), \mathrm{JSS} / \mathrm{JHS}(\mathrm{AOR}=0.26,95 \% \mathrm{Cl}=0.08-0.84), \mathrm{SSS} / \mathrm{SHS}(\mathrm{AOR}=0.22,95 \% \mathrm{Cl}=0.05-1.02)$ and tertiary ( $A O R=0.26,95 \% \mathrm{Cl}=0.08-0.88)$ were less likely to be malnourished compared with those with no formal education. Those with good nutrition-related knowledge were $56 \%$ ( $A O R=0.44,95 \% \mathrm{Cl}=0.18-1.09$ ) less likely to be malnourished than those with poor knowledge; this was however, not statistically significant.

Conclusion: We found a high prevalence of malnutrition among the clients which militates against progress towards achieving the Sustainable Development Goal targets 3.3 and 3.4 of stopping AIDS epidemic and preventing premature deaths from malnutrition. Our findings justify the need for the implementation of innovative interventions by stakeholders in Ghana's health industry to improve the nutritional status of people living with the disease.
\end{abstract}

Keywords: Ghana, HIV/AIDS, Nutritional status, People living with HIV/AIDS, Nutritional knowledge

\footnotetext{
* Correspondence: fsaahpnur14@uhas.edu.gh

2Department of Epidemiology and Biostatistics, School of Public Health, University of Health and Allied Sciences, Hohoe, Ghana

Full list of author information is available at the end of the article
}

(c) The Author(s). 2021 Open Access This article is licensed under a Creative Commons Attribution 4.0 International License, which permits use, sharing, adaptation, distribution and reproduction in any medium or format, as long as you give appropriate credit to the original author(s) and the source, provide a link to the Creative Commons licence, and indicate if changes were made. The images or other third party material in this article are included in the article's Creative Commons licence, unless indicated otherwise in a credit line to the material. If material is not included in the article's Creative Commons licence and your intended use is not permitted by statutory regulation or exceeds the permitted use, you will need to obtain permission directly from the copyright holder. To view a copy of this licence, visit http://creativecommons.org/licenses/by/4.0/. The Creative Commons Public Domain Dedication waiver (http://creativecommons.org/publicdomain/zero/1.0/) applies to the data made available in this article, unless otherwise stated in a credit line to the data. 


\section{Introduction}

The Sustainable Development Goals (SDGs) promulgated by the United Nations in the year 2015 seek to improve health for all at all ages in goal three [1]. Inherent in this goal are targets 3.3 and 3.4, which seek to end the Human Immune Virus and Acquired Immune-deficiency Syndrome (HIV/AIDS) epidemic and reduce premature mortality from non-communicable diseases, including malnutrition [2]. However, these conditions continue to be critical public health issues globally. In 2019, it was estimated that globally, 38 million people are living with HIV/AIDS, with $67 \%$ of those who were aware of their status on antiretroviral treatment [3].

The AIDS stages of the condition make the immune system vulnerable to opportunistic infections with common symptoms being weight loss, fever, diarrhoea, and cough [4]. Poor nutrition, however, reduces the immunity of people living with HIV/AIDS (PLWHA) and results in a quicker progression to the AIDS stage $[5,6]$. An immune dysfunction as a result of HIV/AIDS leads to malnutrition, while poor nutrition decreases the immune system [7]. Undernutrition among PLWHA is known to be caused by depression, reduced appetite, and some common opportunistic infection such as oral thrush.

Good nutrition primes to stronger resistance to the disease, upsurges compliance to the efficacy of antiretroviral treatment, promotes a higher quality of life, protects the organism from immunosuppression, and adjourns the stage of AIDS [5, 6]. Also, it is argued that good nutrition among PLWHA helps to enhance the immune system and decrease the burden of opportunistic infections [8-11].

Three or more antiretroviral drugs have been the standard treatment for HIV/AIDS, which represses viral replication. It is termed the Highly Active Antiretroviral Therapy (HAART) [12]. In 2013, WHO reported that the antiretroviral treatment was accessible to some 12.9 million folks, the treatment significantly enhances the life expectancy and health-related quality of life [12]. HAART in itself influences the normal metabolic processes, therefore affecting the nutritional intake of PLWHA. Hence, nutrition and diet are predominantly significant in the use of the therapy [5]. Understanding nutritional requirements and proper nutritional practices among PLWHA is critical to improving their immune system. A meta-analysis of demographic and health survey data of women in reproductive age from 11 Sub-Saharan African countries including Ghana, for instance showed 10\% had HIV/AIDS-related malnutrition $(\mathrm{BMI}<18.5)$ [13].

In Ghana, HIV prevalence continues to rise with a national prevalence of $1.70 \%$ in 2019 with Volta Region recording a prevalence of $1.28 \%$ [14]. There have been significant achievements in the care, treatment, and support for PLWHA in Ghana since HAART became accessible [15]. However, Nti, Hayford, and OpareObisaw [16] note that one-third of PLWHA in the Eastern Region of Ghana were underweight while $50 \%$ had poor diets. Also, most of the $50 \mathrm{HIV}$-seropositive adults attending a hospital in Accra, had inadequate dietary intake citing cost and knowledge of nutritional requirements as barriers [17]. If services to preserve and prolong the lives of PLWHA, including better nutritional practices are not implemented, attaining projected results will not be possible. We, therefore, investigated the nutrition-related knowledge and attitude, and nutritional status of PLWHA accessing HAART at a public hospital in the Volta Region of Ghana. Our study is relevant in the prevention of HIV/AIDS-related mortalities, in that, it provides the magnitude of poor nutrition and existing knowledge and attitudes among PLWHA in Ghana. These findings will be significant to policies and interventions to improve survival rates and quality of life for PLWHA in the country.

\section{Methods}

The methods were carried out in accordance with relevant guidelines and regulations in this section. We adopted the "Strengthening the Reporting of Observational Studies in Epidemiology" (STROBE) checklist in conducting and reporting this research.

\section{Setting}

The study was carried out at a public hospital in Ho Municipality of the Volta Region, Ghana in 2019. Ho has four hospitals and three clinics with the Ho Teaching Hospital, popularly known as Trafalgar, being the general and referral centre [18]. The hospital has a HAART unit where PLWHA usually visits monthly to access their immunity and medications. The unit has a counselling section that usually takes up the mandate of advising clients on their upkeep. The Municipality has a central market and three tertiary institutions.

\section{Study design}

We adopted a descriptive cross-sectional design in conducting this study. This design allowed to collect quantitative data at a point in time using questionnaires to describe an existing phenomenon of interest, nutritional status. It was appropriate because the study sought to explore nutrition-related knowledge, attitudes, and nutritional status of PLWHA accessing HAART in a public hospital in Ghana.

\section{Study population and sampling}

The study involved people living with HIV/AIDS, accessing HAART at a public hospital, and aged 18 years or older. This population was chosen because they are 
experiencing service that is meant to impact the phenomena of this study; nutritional knowledge and practices among PLWHA. However, health professionals and foreign nationals were excluded.

The study utilised Yamane's [19] sample size formula, $n=\frac{\mathrm{N}}{1+\mathrm{N}(\mathrm{e})^{2}}$ to determine the sample sizes based on the population of PLWHA accessing HAART at the facility, 210. At a 95\% confidence interval, margin of error, $\mathrm{e}=0.05$. Thus, with a $10 \%$ non-response rate, the study used a sample size of 152 PLWHA attending HAART at the public hospital. These respondents were selected using a simple random sampling technique. Using the HAART Register as a sampling frame, the numbers corresponding to each client in the register were written on pieces of paper, rolled into balls, and put into a container. The container was shaken and a rolled paper picked at random until the sample size was obtained. Clients whose numbers were picked were included in the study to make up the required sample.

\section{Procedures}

A person living with HIV/AIDS whose registration number was picked, and consented to participate was interviewed by a trained research assistant. Prior to inclusion in the study, the study processes were explained and assurance of ethical concerns and all other concerns addressed. Data were collected using a semi-structured questionnaire with support of two trained research assistants. The instrument was selfdeveloped based on literature (largely adapted form Abgaryan [5]) and pre-tested among 40 PLWHA in the Hohoe Municipal Hospital and found to have a reliability coefficient, $\alpha$ of 0.742 . Due to the differences in contexts of the previous studies and this study, the validity of the instrument was ensured by giving it to two experts in HIV/AIDS studies to review which resulted in some parts being discarded or remodelled for use. It was made up of four sections A-D; Section A on socio-demographic characteristics, $\mathrm{B}$ on nutrition-related knowledge and healthy diet, $\mathrm{C}$ on the attitude of PLWHA towards healthy nutrition, and D on nutritional status. Respondents who could not read or understand the questionnaire were assisted, and the questions explained to them. To minimize the introduction of bias in the translation, the data collectors were trained on common explanation to all the questions. Completed questionnaires were checked for completeness and validity of responses.

\section{Study variables}

The outcome variable was nutritional status, which was determined using the Body Mass Index (BMI). The explanatory variables were age, sex, marital status, highest educational level, employment status, size of the household, monthly expenditures, as well as the proportion of expenditure spent on food, nutrition-related knowledge and attitude towards nutrition. The nutrition-related knowledge included the understanding of the nutritional requirements for PLWHA and the need for special nutrition while attitude towards nutrition constituted questions assessing behaviour and perception of special nutrition for PLWHA.

\section{Data analysis}

Data collected were entered, cleaned, and analysed using Statistical Package for the Social Sciences (SPSS) version 22.0. The analyses were carried out with descriptive statistics comprising mean, frequency, and percentage, as well as inferential statistics consisting of binary logistic regression. All statistical analyses were considered significant at $p$-values $<0.05$ at $95 \%$ confidence intervals (CI). We performed two binary logistics regression models. We first conducted bivariable model (Model I) using all the explanatory variables. Variables that were significant were then included in our multivariable model (Model II).

There were 20 questions assessing nutrition-related knowledge, and correct responses were graded 1 and wrong responses scored 0 , resulting in a maximum total score of 20. Hence, respondents who had index scores of more than half i.e. 11 or more (indicating correct responses for more than 10 of the 20 knowledge questions) were categorized as having adequate nutritionrelated knowledge. The attitude variable constituted five [5] questions and used a Likert scale of 0-Disagree and 1-Agree to grade, making a maximum index score of 5 . Thus, respondents with attitude scores of more than half i.e. 3 or more (representing positive responses for 3 or more of the 5 attitude statements) were graded as having good attitude towards their nutrition.

\section{Ethical issues}

Ethical approval for this study was obtained from the University of Health and Allied Sciences' Research Ethics Committee. Permission was also sought from the Ho Municipal Health Directorate and the management of the public hospital. Before including participants in the study, written informed consent was obtained, after assurance of optimum levels of anonymity and confidentiality of information provided. Hard copies of the data have been kept under lock and key, while soft copies have been stored on a personal computer with password and backup.

\section{Results}

Socio-demographic characteristics

Table 1 presents the socio-demographic characteristics of the $152 \mathrm{HIV} / \mathrm{AIDS}$ clients attending antiretroviral therapy at the public hospital. Females constituted $77.6 \%$. 
Table 1 Socio-demographic characteristics of respondents

\begin{tabular}{l} 
Socio-demographic variab \\
\hline Sex \\
Male \\
Female \\
Age (in completed years) \\
$\quad<20$ \\
$20-29$ \\
$30-39$ \\
$40-49$ \\
$50-59$ \\
$60+$
\end{tabular}

\section{Marital status}

Never married

Married

Divorced

Widowed

Religion

Christian

Muslim

Traditionalist

\section{Ethnicity}

Akan

Ewe

Ga

Mole-Dagbani

Highest educational level

No formal education

Primary

JSS/JHS

SSS/SHS

Tertiary

\section{Place of residence}

In Ho Municipality

Outside Ho Municipality

Employment status

Employed

Unemployed

Occupation $(n=132)$

Artisan/Skilled worker
Trader
Farmer
Teacher
Retired
Other

\begin{tabular}{ll} 
Frequency & Percentage (\%) \\
\hline 34 & 22.4 \\
118 & 77.6 \\
& \\
6 & 3.9 \\
32 & 21.1 \\
46 & 30.3 \\
32 & 21.1 \\
27 & 17.8 \\
9 & 5.9
\end{tabular}

21.1

54.6

12.5

11.8

18

132

86.8

11.2

2.0
Table 1 Socio-demographic characteristics of respondents (Continued)

\begin{tabular}{lll}
\hline Socio-demographic variable & Frequency & Percentage (\%) \\
\hline Length of being on anti-retroviral therapy & \\
$\quad$ < 6 months & 13 & 8.6 \\
7-11 months & 10 & 6.6 \\
1-2 years & 32 & 21.0 \\
3-4 years & 45 & 29.6 \\
5-10 years & 49 & 32.2 \\
$>10$ years & 3 & 2.0 \\
Received nutritional counselling & & \\
Yes & 148 & 97.4 \\
No & 4 & 2.6 \\
\hline
\end{tabular}

The mean age of the respondents was 39.3 years (S.D. = 12.6). A majority (54.6\%) were married, Christians (86.8\%), and Ewes (77\%). The highest level of education attained by the comparative majority of the respondents (42.1\%) was primary education. Most also lived outside the Ho Municipality (66.4\%) and were employed (86.8\%). Also, $34.9 \%$ of the respondents were engaged in trading as their major occupation. A comparative majority of the respondents $(32.2 \%)$ has been on antiretroviral therapy for 5-10 years. Most (97.4\%) of the respondents had also received nutritional counselling.

Nutrition-related knowledge and attitude among PLWHA Participants' responses to the knowledge and attitude questions is attached as Additional File 1. The nutritionrelated knowledge questions encompassed; expected consumption rates (more, less or the same) for vegetables, grains, meat, and fruits, and sugary, salty, and fatty foods, as well as knowing experts' nutrition recommendation for PLWHA, inter-related link between nutrition and health status of PLWHA.

Table 2 presents the overall level of nutrition-related knowledge among the HIV/AIDS clients. It was realised that, overall, $78.9 \%$ of the respondents had good nutrition-related knowledge. Regarding attitude towards nutrition among the respondents, the questions included perception of maintaining healthy diet, willingness to make diet changes, and perception of healthy diet education. We realised that $74 \%$ of the respondents had good attitude towards their nutrition.

\section{Nutritional status of PLWHA}

The nutritional status of the respondents was determined using the weights and height of the respondents and categorised into Normal and Malnourished (underweight and overweight/obese). From Fig. 1, 14\% of the respondents were underweight, whereas $28 \%$ were overweight/obese. 
Table 2 Level of nutrition-related knowledge and attitude of respondents

\begin{tabular}{lll}
\hline Variable & Frequency & Percentage (\%) \\
\hline Level of knowledge & & \\
Poor knowledge & 32 & 21.1 \\
Good knowledge & 120 & 78.9 \\
Nutritional attitude & & \\
Poor attitude & 39 & 26.0 \\
Good attitude & 113 & 74.0 \\
\hline
\end{tabular}

Thus, $42 \%$ of the respondents were malnourished (either underweight or overweight/obese).

\section{Predictors of nutritional status among PLWHA}

Our result in Table 3 shows that PLWHA with primary $(\mathrm{COR}=0.38,95 \% \mathrm{CI}=0.08-1.93, p=0.245), \quad \mathrm{JSS} / \mathrm{JHS}$ $(\mathrm{COR}=0.2, \quad 95 \% \mathrm{CI}=0.07-0.73, \quad p=0.012), \quad \mathrm{SSS} / \mathrm{SHS}$ $(\mathrm{COR}=0.21,95 \% \mathrm{CI}=0.05-0.96, p=0.044)$, and tertiary $(\mathrm{COR}=0.22,95 \% \mathrm{CI}=0.07-0.74, p=0.014)$ were less likely to be malnourished compared with those without formal education. Also, PLWHA who had good nutrition-related knowledge were 62\% (COR =0.38, 95\% $\mathrm{CI}=0.16-0.92, p=0.031$ ) less likely to be malnourished than those with poor nutrition-related knowledge.

After adjusting for presence of other significant variables, we found that PLWHA with primary (AOR = $0.36,95 \% \mathrm{CI}=0.07-1.84, p=0.222)$, JSS $/ \mathrm{JHS}(\mathrm{AOR}=0.26$, $95 \% \mathrm{CI}=0.08-0.84, p=0.025), \mathrm{SSS} / \mathrm{SHS}(\mathrm{AOR}=0.22,95 \%$ $\mathrm{CI}=0.05-1.02, p=0.053)$ and tertiary $(\mathrm{AOR}=0.26,95 \%$ $\mathrm{CI}=0.08-0.88, p=0.031$ ) were less likely to be malnourished compared with those without formal education.

Also, PLWHA who have good nutrition-related knowledge were $56 \%$ (AOR $=0.44,95 \% \mathrm{CI}=0.18-1.09$, $p=0.076)$ less likely to be malnourished than those who had poor nutrition-related knowledge.

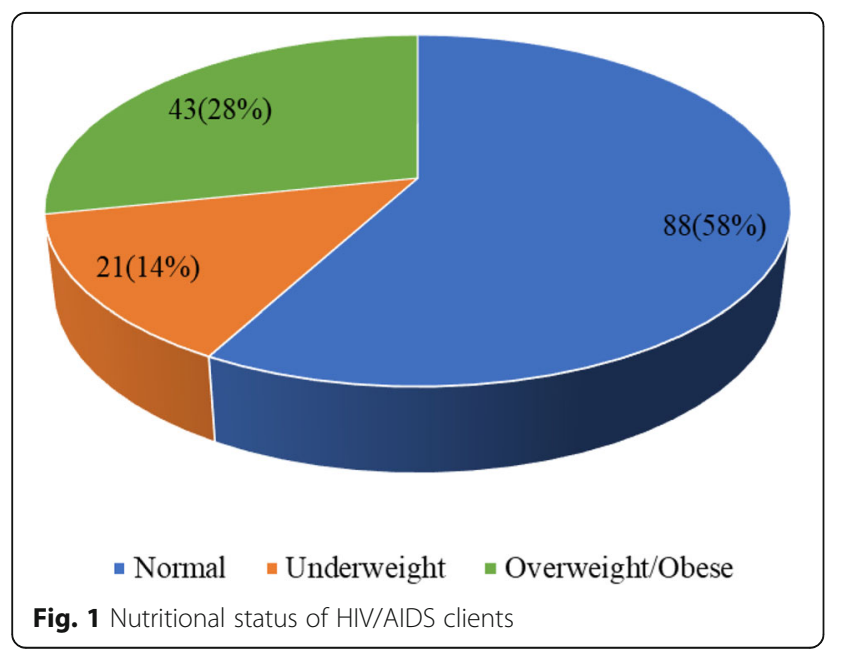

\section{Discussion}

We examined the nutrition-related knowledge and attitude, and status of HIV/AIDS clients accessing HAART service in a public hospital in the Volta Region of Ghana. We found that most of the respondents (78.9\%) had good nutrition-related knowledge. The finding that most of the PLWHA had good nutrition-related knowledge is in congruence with that of Anand and Puri [20], where overall nutrition-related knowledge was found to be good among $80 \%$ of PLWHA. However, this finding differs from those of Devika and Thahira [21] and Abgaryan [5] which reported lower proportions of PLWHA, $48 \%$, and $68.8 \%$ respectively, having good nutritionrelated knowledge. The high proportion of good nutrition-related knowledge in our study could have resulted from nutritional counselling and education provided during the HAART clinic sessions, a common component in HAART service.

We also found that nutritional attitude was good among most of the respondents (74\%). Regarding most of PLWHA having a good attitude towards their nutrition, this is consistent with Abgaryan's [5] finding in a similar study where $71.2 \%$ of PLWHA had good attitude towards nutrition. Nevertheless, this finding disagrees with those of Anand and Puri [20] and Nzeagwu and Uwaegbute [22], who noted that less than half of PLWHA, 38\%, and 49.2\% respectively, had good attitude towards their nutrition. The finding of the current study could be attributed to the appropriate understanding obtained during the HAART clinic sessions. Nutrition counselling has been argued to bring about behaviour change [20]. Due to this, PLWHA are willing and supportive of nutrition improvement measures.

Also, we found that $13.8 \%$ of the respondents were underweight, whereas a quarter $(28.3 \%)$ were overweight/obese. Generally, $42 \%$ of the respondents were malnourished and that respondents' level of education and level of nutrition-related knowledge was found to statistically influence their nutritional status. Our finding that $13.8 \%$ were underweight is in congruence with the finding of Nzeagwu and Uwaegbute [22], which noted that $12.5 \%$ of PLWHA were underweight. However, this is lower than that of Thapa et al. [23], which revealed that one in five PLWHA was underweight. Also, the prevalence of obesity/overweight found in this study is lower than those found in the studies by Giudici, Duran, and Jaime [24] and Nzeagwu and Uwaegbute [22]. In these studies, the researchers found $34 \%$ and $36.7 \%$ respectively, were overweight/obese. Again, the overall malnutrition prevalence of $42 \%$ found in our study supports the finding of Kassa, Alle, and Tesfu [25] which reported $43 \%$ of prisoners living with HIV/AIDS being malnourished. The prevalence was however, higher than studies carried out in Gueckedou, Guinea (38\%) [26], 
Table 3 Predictors of Nutritional Status among PLWHA

\begin{tabular}{|c|c|c|c|c|}
\hline \multirow[t]{2}{*}{ Variable } & \multicolumn{2}{|c|}{ Nutritional status } & \multirow{2}{*}{$\begin{array}{l}\text { Model I } \\
\text { COR }(95 \% \mathrm{Cl}) p \text {-value }\end{array}$} & \multirow{2}{*}{$\begin{array}{l}\text { Model II } \\
\text { AOR }(95 \% \mathrm{Cl}) p \text {-value }\end{array}$} \\
\hline & $\begin{array}{l}\text { Malnourished } \\
\mathrm{n}(\%)\end{array}$ & $\begin{array}{l}\text { Normal } \\
\mathrm{n}(\%)\end{array}$ & & \\
\hline \multicolumn{5}{|l|}{ Sex } \\
\hline Male & $12(35.3)$ & $22(64.7)$ & Ref & \\
\hline Female & $52(44.1)$ & $66(55.9)$ & $0.69(0.31-1.53) 0.363$ & \\
\hline \multicolumn{5}{|l|}{ Age group } \\
\hline$<20$ & $3(50.0)$ & $3(50.0)$ & Ref & \\
\hline $20-29$ & 13(40.6) & 19(59.4) & $2.00(0.24-16.61) 0.521$ & \\
\hline $30-39$ & $20(43.5)$ & $26(56.5)$ & $1.37(0.29-6.48) 0.693$ & \\
\hline $40-49$ & 15(46.1) & $17(53.1)$ & $1.54(0.34-6.92) 0.574$ & \\
\hline $50-59$ & 10(37.0) & 17(63.0) & $1.76(0.37-8.32) 0.473$ & \\
\hline $60+$ & $3(33.3)$ & $6(66.7)$ & $1.18(0.24-5.77) 0.841$ & \\
\hline \multicolumn{5}{|l|}{ Marital status } \\
\hline Single & 14(43.8) & 18(56.3) & Ref & \\
\hline Married & $34(41.0)$ & 49(59.0) & $0.97(0.30-3.11) 0.962$ & \\
\hline Divorced & $8(42.1)$ & $11(57.9)$ & $0.87(0.31-2.42) 0.786$ & \\
\hline Widowed & $64(42.1)$ & 10(55.6) & $0.91(0.25-3.34) 0.886$ & \\
\hline \multicolumn{5}{|l|}{ Religion } \\
\hline Christian & $57(43.2)$ & $75(56.8)$ & Ref & \\
\hline Muslim & $6(35.3)$ & $11(64.7)$ & $1.52(0.13-17.18) 0.735$ & \\
\hline Traditionalist & $1(33.3)$ & $2(66.7)$ & $1.09(0.08-14.66) 0.948$ & \\
\hline \multicolumn{5}{|l|}{ Ethnicity } \\
\hline Akan & $13(56.5)$ & $10(43.5)$ & Ref & \\
\hline Ewe & $45(38.5)$ & $72(61.5)$ & $1.30(0.07-23.43) 0.859$ & \\
\hline Ga & $5(50.5)$ & $5(50.5)$ & $0.62(0.04-10.24) 0.742$ & \\
\hline Mole-Dagbani & $1(50.0)$ & $1(50.0)$ & $1.00(0.05-20.83) 1.000$ & \\
\hline \multicolumn{5}{|l|}{ Highest level of education } \\
\hline No formal education & $5(50.5)$ & $5(50.5)$ & Ref & Ref \\
\hline Primary & $24(37.5)$ & $40(62.5)$ & $0.38(0.08-1.93) 0.245$ & $0.36(0.07-1.84) 0.222$ \\
\hline JSS/JHS & $5(35.7)$ & $9(64.3)$ & $0.23(0.07-0.73) 0.012^{*}$ & $0.26(0.08-0.84) 0.025^{*}$ \\
\hline SSS/SHS & $17(37.0)$ & $29(63.0)$ & $0.21(0.05-0.96) 0.044^{*}$ & $0.22(0.05-1.02) 0.053$ \\
\hline Tertiary & 13(72.2) & $5(27.8)$ & $0.22(0.07-0.74) 0.014^{*}$ & $0.26(0.08-0.88) 0.031^{*}$ \\
\hline \multicolumn{5}{|l|}{ Place of Permanent living } \\
\hline Inside Ho Municipality & 20(39.2) & $31(60.8)$ & Ref & \\
\hline Outside Ho Municipality & $44(43.6)$ & $57(56.4)$ & $0.84(0.42-1.66) 0.608$ & \\
\hline \multicolumn{5}{|l|}{ Employment status } \\
\hline Yes & $53(40.2)$ & 79(59.8) & Ref & \\
\hline No & $11(55.0)$ & $9(45.0)$ & $0.55(0.21-1.41) 0.215$ & \\
\hline \multicolumn{5}{|c|}{ Duration of being on therapy } \\
\hline Less than 6 months & $6(46.2)$ & $7(53.8)$ & Ref & \\
\hline 7-11 months & $5(50.0)$ & $5(50.0)$ & $1.71(0.12-23.94) 0.689$ & \\
\hline $1-2$ years & 13(40.6) & 19(59.4) & $2.00(0.13-29.81) 0.615$ & \\
\hline $3-4$ years & $20(44.4)$ & 25(55.6) & $1.34(0.11-16.70) 0.806$ & \\
\hline $5-10$ years & 19(38.8) & $30(61.2)$ & $1.60(0.13-18.94) 0.709$ & \\
\hline
\end{tabular}


Table 3 Predictors of Nutritional Status among PLWHA (Continued)

\begin{tabular}{|c|c|c|c|c|}
\hline \multirow[t]{2}{*}{ Variable } & \multicolumn{2}{|c|}{ Nutritional status } & \multirow{2}{*}{$\begin{array}{l}\text { Model I } \\
\text { COR }(95 \% \mathrm{Cl}) p \text {-value }\end{array}$} & \multirow{2}{*}{$\begin{array}{l}\text { Model II } \\
\text { AOR }(95 \% \mathrm{Cl}) p \text {-value }\end{array}$} \\
\hline & $\begin{array}{l}\text { Malnourished } \\
\mathrm{n}(\%)\end{array}$ & $\begin{array}{l}\text { Normal } \\
\mathrm{n}(\%)\end{array}$ & & \\
\hline More than 10 years & 1(33.3) & $2(66.7)$ & $1.27(0.11-14.95) 0.851$ & \\
\hline \multicolumn{5}{|c|}{ Have you received nutritional counselling } \\
\hline Yes & $62(41.9)$ & $86(58.1)$ & Ref & \\
\hline No & $2(50.0)$ & $2(50.0)$ & $0.72(0.0-5.26) 0.747$ & \\
\hline \multicolumn{5}{|c|}{ Nutrition-related knowledge } \\
\hline Poor Knowledge & $8(25.0)$ & $24(75.0)$ & Ref & Ref. \\
\hline Good Knowledge & $56(46.7)$ & $64(53.3)$ & $0.38(0.16-0.92) 0.031^{*}$ & $0.44(0.18-1.09) 0.076$ \\
\hline \multicolumn{5}{|c|}{ Attitude towards nutrition } \\
\hline Poor attitude & 17(43.6) & $22(56.4)$ & Ref & \\
\hline Good attitude & 47(41.6) & $66(58.40$ & $1.08(0.52-2.26) 0.828$ & \\
\hline
\end{tabular}

${ }^{*} p<0.05$ Ref. Reference category

Tanzania (23\%) [27] and Guinea (19.6\%) [28]. Yet, the finding of the current study is lower than that of Nzeagwu and Uwaegbute [22], where $49.2 \%$ of the PLWHA were malnourished. This could be attributed to the fact that most HIV clients may have limited food choices and the opportunity to manage their nutrition due to their socio-economic status.

We also found that respondents' highest level of education and level of nutrition-related knowledge influenced their nutritional status. This finding is in congruent to that of Thapa et al. [23], which posited that educational status significantly influence the nutritional status of PLWHA. Also, the current finding supports the findings of Nti et al. [16], that there is a positive correlation between nutrition knowledge and nutritional status among PLWHA. This may be due to knowledge providing a better understanding of the special nutritional needs of PLWHA, subsequently making it possible to engage in nutritional practices that will in turn positively strengthen their nutritional status as argued by Gaikwad et al. [29] in an Indian study.

\section{Strengths and limitations}

This study relied on verbal reports in measuring attitude of respondents towards nutrition. There is, thus, the tendency that respondents might have provided favourable responses during the data collection.

\section{Conclusion}

Although nutrition-related knowledge and attitude among PLWHA were good, this did not correspond to the high prevalence of malnutrition. This finding implies that most PLWHA are at risk of deteriorating immunity as a result of poor nutrition. Potentially, this may increase their risk of exposure to opportunistic infections such as tuberculosis, reducing their survival rates and quality of life. Ghana may, thus, not be able to achieve the SDG targets 3.3 and 3.4 targets of stopping the AIDS epidemic and reducing premature deaths from noncommunicable conditions, including poor nutrition.

In order to forestall these findings and accelerate Ghana's progress towards the achievement of the SDGs, the Ghana Health Services should intensify and employ innovative approaches to nutritional education and counselling for PLWHA. Also, HIV/AIDS stakeholders such as the Ghana Aids Commission and the Ghana Health Service should ensure sustained attention to the prevention, early detection, and treatment of malnutrition throughout the stages of HIV. Additionally, social support systems with a focus on assisting PLWHA should be instituted by the Ministry of Health and the Ghana Health Service to ensure that there is food security for individuals with low socio-economic status.

\section{Abbreviations}

SDGs: Sustainable Development Goals; WHO: World Health Organisation; STROBE: Strengthening the Reporting of Observational Studies in Epidemiology; GSS: Ghana Statistical Service; HAAR: Highly Active AnteRetroviral Treatment; BMI: Body Mass Index; PLWHA: People living with HIV/ AIDS

\section{Supplementary Information}

The online version contains supplementary material available at https://doi. org/10.1186/s40795-021-00418-2.

Additional file 1.

Acknowledgements

We thank the management of the hospital where the study was carried out.

Authors' contributions

BMN: Conceptualization, Ethical Approval Application, Methodology, Investigation, Data Collection and Entry. FIS: Conceptualization, Methodology, Investigation, Software, Data curation, Validation, Original draft preparation, Reviewing and Editing. PKA: Conceptualization, Visualization, Supervision, 
Validation, Reviewing and Editing. HA: Conceptualization, Methodology, Visualization, Supervision, Validation, Reviewing and Editing. KK: Conceptualization, Supervision, Reviewing and Editing. The author(s) read and approved the final manuscript.

\section{Funding}

None.

\section{Availability of data and materials}

The datasets used and/or analysed during the current study are available from the corresponding author on reasonable request.

\section{Declarations}

\section{Ethics approval and consent to participate}

Ethical approval for this study was obtained from the University of Health and Allied Sciences' Research Ethics Committee (Reference: UHAS-REC A.4 [53] 18-19). Also, written informed consent was obtained from all participants before inclusion in the study.

\section{Consent for publication}

Not applicable.

\section{Competing interests}

The authors declare that they have no competing interests.

\section{Author details}

'Department of Family and Community Health, School of Public Health, University of Health and Allied Sciences, Hohoe, Ghana. ${ }^{2}$ Department of Epidemiology and Biostatistics, School of Public Health, University of Health and Allied Sciences, Hohoe, Ghana. ${ }^{3}$ Department of Population and Behavioural Sciences, School of Public Health, University of Health and Allied Sciences, Hohoe, Ghana. ${ }^{4}$ Department of Population and Health, University of Cape Coast, Cape Coast, Ghana.

Received: 20 December 2020 Accepted: 10 March 2021

Published online: 27 May 2021

\section{References}

1. Osborn D, Cutter A, Ullah F. Universal sustainable development goals: understanding the transformational challenge for developed countries. New York: Stakeholder Forum; 2015.

2. World Health Organisation (WHO). WHO HIV/AIDS. 2016. Retrieved from WHO website http://who.int/hiv/en/ on Jan. 1, 2020.

3. World Health Organisation (WHO). HIV/AIDS. 2020. Retrieved from WHO website https://www.who.int/news-room/fact-sheets/detail/hiv-aids on Feb. 23, 2021.

4. World Health Organization (WHO). Sustainable development goals (SDGs): Goal 3. Target 3.5 Strengthen the prevention and treatment of substance abuse, including narcotic drug abuse and harmful use of alcohol [poster]. Manila: WHO Regional Office for the Western Pacific; 2016.

5. Abgaryan S. Nutritional knowledge, attitude and practices among people living with HIV in Armenia: a cross-sectional survey. Yerevan: School of Public Health American University of Armenia; 2015.

6. Duggal S, Chugh TD, Duggal AK. HIV and malnutrition: effects on immune system. Clin Dev Imunol 2012;2012:784740

7. Oguntibeju OO, Van FS. The interrelationship between nutrition and the immune system in HIV infection: a review. Pak J Biol Sci. 2007:10(24):432738. https://doi.org/10.3923/pjbs.2007.4327.4338.

8. Gebremichael DY, Hadush KT, Kebede EM, Zegeye RT. Food insecurity, nutritional status, and factors associated with malnutrition among people living with HIV/AIDS attending antiretroviral therapy at public health facilities in west Shewa zone, Central Ethiopia. Biomed Res Int. 2018;2018: 1913534.

9. World Health Organization. Nutrition activities in care, support and treatment of HIV/AIDS situation analysis for SEAR countries: based on preliminary desk review and inputs from member countries. Geneva: WHO; 2007.

10. Republic of Kenya Ministry of Health. Kenyan national guidelines on nutrition and HIV/AIDS. Nairobi: Ministry of Health, Government of Kenya; 2006.
11. United Nations High Commissioner for Refugees (UNHCR), World Food Programme (WFP). Integration of HIV/AIDS activities with food and nutrition support in refugee settings: specific programme strategies. Geneva: UNHCR; 2004.

12. World Health Organization (WHO). WHO Antiretroviral therapy. 2014. Retrieve from WHO website http://www.who.int/topics/antiretroviral_thera py/en/ on Jan. 1, 2020

13. Uthman OA. Prevalence and pattern of HIV-related malnutrition among women in sub-Saharan Africa: a meta-analysis of demographic health surveys. BMC Public Health. 2008;8(1):226. https://doi.org/10.1186/1471-24 58-8-226.

14. Ghana AIDS Commission. Ghana's HIV Fact sheet 2019. Accra: Ghana AIDS Commission; 2020

15. Agyekum O, Asare K, Nayembil DA, Agyapong GO, Frimpong KO, Akanzeriba AA. Nutritional knowledge, attitude and intake among hiv patients: a study at Agogo Presbyterian Hospital, Ghana. Appl Res J. 2016; 1(3):35-43.

16. Nti CA, Hayford J, Opare-Obisaw C. Nutrition knowledge, diet quality and nutritional status of people living with HIV (PLHIV) in Ghana. Food Public Health. 2012;2(6):219-27.

17. Wiig K, Smith C. An exploratory investigation of dietary intake and weight in human immunodeficiency virus-seropositive individuals in Accra, Ghana. J Am Diet Assoc. 2007;107(6):1008-13. https://doi.org/10.1 016/j.jada.2007.03.002

18. Ghana Statistical Service (GSS). District Analytical Report: Ho Municipality. Accra: GSS; 2014

19. Yamane T. Statistics, an introductory analysis 2nd edition. New York: Horper and Row; 1967.

20. Anand D, Puri S. Nutritional knowledge, attitude, and practices among HIVpositive individuals in India. J Health Popul Nutr. 2013:31(2):195.

21. Devika I, Thahira BA. Assessment of nutritional knowledge, attitude and practice among HIV infected women with art treatment in India. Int J Med Health Res. 2016:2(7):03-7.

22. Nzeagwu OC, Uwaegbute A. Nutrition-related behaviors and nutritional status of HIV adult patients. Adv Nutr. 2016:7(1):41A

23. Thapa R, Amatya A, Pahari DP, Bam K, Newman MS. Nutritional status and its association with quality of life among people living with HIV attending public anti-retroviral therapy sites of Kathmandu Valley, Nepal. AIDS Res Ther. 2015;12(1):14. https://doi.org/10.1186/s12981-015-0056-9.

24. Giudici KV, Duran AC, Jaime PC. Inadequate food intake among adults living with HIV. Sao Paulo Med J. 2013;131(3):145-52. https://doi.org/10.1590/151 6-3180.2013.1313478.

25. Kassa T, Alle A, Tesfu M. Assessment of nutritional status and associated factors among prisoners living with HIV/AIDS in Kality prison, Addis Ababa, Ethiopia. J AIDS Clin Res. 2017;8(6):1-6.

26. Médecins Sans Frontières (MSF). Guinea: MSF exposes emergency nutritional and medical needs in Guinean prisons. Brussel: Médecins Sans Frontières; 2009.

27. Mwakyoso ML. Nutritional assessment of prisoners living with HIV/AIDS in selected prisons in Tanzania. Morogoro: Sokoine University of Agriculture; 2013

28. Sidibé S, Magassouba AS, Delamou A, Magaboussa FB, Sandouno SD, Kra KÉ, Conte N. Nutritional status of people living with HIV/AIDS in the Ratoma community medical center (Republic of Guinea). Med Sante Trop. 2017; 27(1):77-81. https://doi.org/10.1684/mst.2017.0654.

29. Gaikwad SS, Giri PA, Suryawanshi SR, Garg S, Singh MM, Gupta VK. Impact of nutritional counselling on dietary practices and body mass index among people living with HIV/AIDS at a tertiary care teaching hospital in Mumbai. J Med Nutr Nutraceuticals. 2013:2(2):99. https://doi. org/10.4103/2278-019X.114721.

\section{Publisher's Note}

Springer Nature remains neutral with regard to jurisdictional claims in published maps and institutional affiliations. 